\title{
Quality and Inequality of Jobs Created in MENA Region: The Case of Labor Market in Jordan
}

\author{
Ibrahim M. Alhawarin (Corresponding author) \\ Assistant Professor, Al-Hussein Bin Talal University \\ Ma'an, Jordan \\ E-mail: ibrahim981@yahoo.co.uk \\ Mamdouh Salamat \\ National Center for Human Resources Development (NCHRD) \\ Al Jubeiha 11941, Jordan \\ E-mail: mamdouh@nchrd.gov.jo
}

$\begin{array}{ll}\text { Received: August 3, } 2011 & \text { Accepted: October 8, } 2011 \quad \text { Published: January 16, } 2012 \\ \text { doi:10.5539/ijbm.v7n2p200 } & \text { URL: http://dx.doi.org/10.5539/ijbm.v7n2p200 }\end{array}$

The study was funded by Canada's International Development Research Centre (IDRC) and was carried out under the leadership of the Population Council (West Asia and North Africa), Egypt.

\begin{abstract}
Using micro-level data sets, the current study constructs a Job Quality Index (JQI) for Jordanian wage and salary workers. Due to the unavailability of data for some years, the study covers only the period 2000-07. Factor Analysis is utilized to compile the index based on the following four dimensions: adequate earnings; underemployment and overemployment (which together represent adequate working hours); and social security. The main findings of the study are as follows:

(1) The JQI appears to have improved in 2007 compared to the mid-2000s, reaching similar levels of those prevailing in 2000. (2) There exists a persistent gender gap in favor of male workers, whose jobs are characterized by a higher JQI. This finding does not change even when taking into account other intervening variables, particularly a worker's age. Good jobs as a percentage of total jobs held by females appear to decline in 2007, unlike males, whose share of good jobs has grown in the same year. Therefore, no sign of convergence in job quality between males and females is detected. (3) JQI varies across education levels, however, less obviously. Workers with basic education and lower are found to obtain considerably poorer jobs and jobs generally characterized with lower JQIs. (4) The JQI differs across age groups. New entrants to the labor market and workers on the verge of retirement are more likely to have lower job quality in comparison with other workers belonging to age groups in the middle of their work lives. (5) The quality of jobs in agricultural activities is found to be on average lower than other activities. On the other hand, real estate activities tend to have higher job quality ratings than other sectors, especially in 2007.
\end{abstract}

Keywords: Job quality, Decent work, Labor market in developing countries, Gender gap, Jordan

\section{Introduction}

The International Labor Organization (ILO) has developed the notion of "decent work," emphasizing it as an imperative element of labor market policy for both developing and developed countries. Therefore, the right of access to productive jobs in an environment granting workers-including women and new entrants freedom, equality, security, and dignity has become a global priority. Subsequently, issues related to decent work have received increasing attention, centered mainly on conceptualizing it more clearly, and developing and compiling relevant indicators that can be utilized to evaluate levels of the quality of jobs in an economy. Jordan, as a small developing country, has witnessed remarkable changes since 1989, when it decided to restructure and liberate its economy with the assistance of the World Bank (WB) and the International Monetary Fund (IMF). In 2000, Jordan gained accession to the World Trade Organization (WTO), followed by other free trade agreements 
signed with various trade partners, notably the USA in 2000. In addition, profound legislative and policy adjustments have been carried out in the labor market. For example, the country has altered its labor laws and minimum wage levels several times since 1990. However, the economy continues to suffer from a persistent level of high unemployment hovering around $14 \%$. The number of jobs created every year, which stands at 69,000 jobs in 2009 (Jordan's Department of Statistics [DOS], 2010) could not keep pace with the increasing rate of newcomers to the labor market. In addition to unemployment, the country's focus has been directed toward poverty alleviation. Despite the focus on Jordan's labor market and employment growth research by local researchers and international bodies such as the World Bank, there is no study that systematically evaluates the quality of jobs created in the economy. In the context of Jordan, the current study comes as the first attempt to examine job quality, with the hope of attracting more attention to this fertile topic. Indeed, further research is needed in this area, particularly designing regular surveys that provide more accurate, relevant, and comprehensive job quality data. The lack of data is undoubtedly a serious obstacle facing research on decent work and job quality, particularly in developing countries (Bazillier, 2008). Using different data sets for the period 2000-07, this study aims to principally draw up a JQI for wage and salary workers in Jordan's labor market. By constructing a JQI, the study attempts primarily to answer the following critical questions: (1) Does the JQI in Jordan deteriorate over time? (2) Is there a difference in the JQI for female workers and male workers? If yes, does the gap worsen over time? (3) What are the influences of education, age, and economic activity on the JQI in Jordan?

The rest of the paper proceeds as follows. After an overview of the Jordanian economy and labor market in the next section, the third section deals with the data and methodology utilized in the study. Main findings of the study are analyzed in the fourth section, followed by the conclusion of the study in fifth section.

\section{Stylized Facts on Jordan's Economy and Labor Market}

Jordan is a small Middle-Eastern country with a nominal gross domestic product reaching USD 15,832.6 billion in 2007 (Central Bank of Jordan, 2007). It is characterized by limited natural resources and a noticeable dependency on external financial inflows, particularly foreign aid, foreign debt, and workers' remittances. Internationally, Jordan is classified as a lower middle-income economy. Since 1989, it has implemented an ambitious program of economic reform with the support of the IMF and the World Bank, to restructure the economy with an aim of boosting economic growth and enhancing the role of the private sector in the economy. In line with this aim, several additional key actions have been taken, (e.g., revision of investment acts, ratification of intellectual property rights laws and other important laws, and free trade agreements with trade partners). However, despite endeavors to alleviate ongoing socio-economic challenges, the country continues to suffer from several problems, chiefly poverty and unemployment. With respect to poverty, a significant proportion of the population lives under the poverty line. Unemployment, which is particularly acute among young adults and women, averages around $14 \%$. The economy's ability to generate employment is currently not keeping pace with the large numbers of job seekers. Graduates from higher education are a particular source of newcomers to labor market as the number of higher education graduates has increased rapidly since 1990 and is expected to rise further over the next decade (UNESCO Institute for Statistics \& OECD, 2005). Table 1 shows average unemployment rates for all workers and by gender for the period 2000-07. Despite a slight decrease in 2007, unemployment rates have been relatively high in comparison with international and regional figures. Essentially, unemployment is more prevalent among the female labor force. High rates of unemployment signal a deficiency in the labor market, deepening poverty incidence, and spread indecent standards of living. The availability of employment is considered among the basic rights of people, thus lying at the center of the decent work issue (see Anker et al, 2003).

The labor force participation rate in Jordan averaged around 38.4\% in the period 2000-07 (see Table 2), while the labor force amounted to 1.312 million participants in 2007 with a large gender disparity. Jordan's labor market has one of the lowest female economic participation rates in world. Women constitute $49 \%$ of the population (5.8 million in 2008) and have a similar percentage regarding the number of female students enrolled in education. However, women's economic participation rate does not exceed $15 \%$, while that of male workers reaches nearly $64.3 \%$.

\section{Data Sources and Methodology}

Obviously, job quality is a multidimensional issue. Thus, studies on decent work and job quality have documented an extensive list of indicators. In addition to employment and income opportunities for all, respect for fundamental work rights and standards, social protection and security, and social dialogue and tripartism are emphasized by the ILO as the principal elements defining decent work (Somavia, 2004). Therefore, wages and salaries alone are not able to gauge the full complexity of job quality (Acemoglu, 2001). Among other indicators, the literature has identified job security, health and safety, worker voice, paid vacation, paid sick days, working 
hours and involuntary part time, low wage share, and commuting time as fundamental aspects of job quality and decent work (e.g. Anker et al, 2003; Enchautegui, 2008; Green, 2006; Howell and Diallo, 2007; Leschke et al, 2008; Lower-Basch, 2007). However, lack of data has constrained obtaining a broader range of job quality indicators at both macro and micro types of analysis for Jordan. The Jordanian data sources applicable for JQI purposes miss several factors of job quality. Generally speaking, no single source of data provides the minimum number of variables that can be utilized to construct a representative JQI. Also, the accessible micro-level cross section data sets as a whole contain a limited number of indicators relevant for job quality investigation. These indicators include: wages and salaries, social security coverage, and working hours, from which it is possible to measure two further variables, namely overemployment and underemployment.

Three micro data sets are employed in this study to compose a single set that contains the later mentioned four indicators. These sources are as follows:

The Employment and Unemployment Survey (EUS) for the period 2000-2007: The EUS is a systematic large-scale survey distributed quarterly, four rounds each year, except the survey of 2004 when the Jordanian Department of Statistics (DOS) carried out only one round. The EUS collects data on various demographical and labor market characteristics. Most importantly, data are available on gender, age, education, wage (in categories), economic sector (public and private), economic activity (agriculture, industry, etc.), employment (economically active and inactive, unemployed, employment status), marital status, and area of residence. Table 3 outlines the EUS for the period utilized in the study, showing the total number of participants and number of wage and salary workers by gender.

The Income and Expenditure Survey (IES) administered in 2006: The IES is different from the EUS as it primarily aims to gather information on household income sources and expenditure channels. However, it incorporates similar questions to those asked by the EUS - almost the same demographical and occupational dimensions are collected. With respect to earnings, the IES has the benefit of asking workers to provide their actual annual wages and salaries rather than inviting them to indicate which wage category correlates with their earnings. Table 4 shows the number of individuals that participated in the survey in 2006, in addition to the number of wage and salary workers by gender.

Social Security Department Records (SSR): The Social Security Department (SSD) keeps records on all individuals participating in and benefiting from the social security fund. The records give details on age, gender, economic sector and activity, as well as monthly wages. A drawback of SSR is that it does not incorporate information on education. The number of records for each year by gender is displayed in Table 5 .

What follows presents the job quality variables utilized in this study:

Real Wages and Salaries: A standard feature of the several large-scale surveys carried out by the DOS is classifying monthly wages and salaries into a limited number of categories. Of course, this procedure may influence researchers' ability to accurately examine the role of wages and salaries in job quality. Only the IES of 2006 provides detailed information on actual annual wage and salaries per worker. Earlier sets of IES data provide similar information on earnings and other variables, but unfortunately only for households (all annual wages and salaries of household members are aggregated in a single number). On the other hand, the EUS has the benefit of providing annual detailed cross-section data unlike the IES. That said, bearing in mind the importance of having detailed information per worker over different years for the purpose of compiling JQI, it was decided to base the analysis primarily on the EUS and partly on the IES. We rely on the IES to facilitate fitting actual wages and salaries for the EUS. Much of the applied work of earnings function estimation applies a version of Mincerian wage equations. The following Mincer-type wage function is estimated in this study for the IES earnings data:

$$
\ln \mathrm{Y}=\alpha+\beta_{\mathrm{i}} \mathrm{S}+\gamma \mathrm{E}+\delta \mathrm{E}^{2}+\theta_{\mathrm{i}} \mathrm{Z}+\varepsilon
$$

Where $\mathrm{S}$ denotes different levels of education, $\ln Y$ stands for the natural logarithm of monthly wages and salaries. To convert wage data into monthly, IES annual wage data was divided by (12). $E$ is the experience of labor which was measured as commonly practiced using worker's age, $E^{2}$ a quadratic term of experience included to reflex the concavity of earnings profiles (Harmon et al, 2003), $Z$ is a vector of other variables (economic sector, gender, economic activity) and $\varepsilon$ is the random error term. Appendix 2 reports the results of regression of IES wage data. Fortunately, the EUS data set contains the same explanatory variables used in regressing wages and salaries of the IES. Therefore, the explanatory variables were recoded similarly to allow the process of fitting continuous wage and salary data for the EUS. However, the one obstacle that remains is how to account for wage and salary growth rate over time To solve the latter problem, we employed the above equation to regress wages and salaries for the EUS, approximated by the average wage of each category, with the same explanatory variables in addition to dummy variables representing the years 2000-07 (Appendix 3 reports 
the results). Coefficients attached to year dummies were then used to proxy for annual growth rates in nominal wages and salaries. STATA statistical software, version 9.1, was utilized to carry out all the primary analysis of the study. STATA eased prediction of natural logarithm values of wages and salaries for the EUS based on IES data. Those values were then adjusted to annual growth rates measured from the EUS data. Finally, the fitted wages and salaries were anti-logged to arrive at nominal actual values, which were subsequently converted into real values using the Consumer Price Index (CPI) measured by the DOS. A standardized real wages and salaries variable was finally created using the following equation: Standardized value $=($ value - minimum $) /($ maximum -minimum).

Social Security Coverage: Social security is considered as among the essential characteristics of good jobs. Neither the EUS nor other available DOS surveys offer information on social security coverage at the worker level. Accordingly, the SSR data was drawn on to proxy for the probability of being covered by social security. Similar steps to those applied in the case of fitting nominal wages and salaries were conducted to introduce a new variable standing for social coverage probability. The SSD is the main Jordanian agency responsible for social coverage. Therefore, to a great extent one may assume that SSR data encloses sufficient information on the social insurance coverage for workers in Jordan. In addition to the fact that both SSR and EUS data are available for the same period (2000-07), their data take into account several worker background variables, including age, economic sector, economic activity, and gender. The later variables were recoded similarly in both data sets. Using STATA, SSR and EUS data were collapsed into different groups, where every group in the SSR matched a similar group in the EUS. The EUS was considered to contain all the workers in the economy, while the SSR was assumed to include only those enjoying social security. The grouped data extracted from the two sets were merged into a single set that contained the group variables and two additional variables. These are the number of all workers in a specific group, which came from the EUS, and the number of covered workers, which was collapsed from SSR. Dividing the number of covered workers by the number of all workers gave the probability of a worker from a particular group to be socially covered, which was denoted as the social security probability. To have a more robust prediction of social coverage, the analysis involved a further step. The social security probability was regressed on the group variables (Appendix 1 displays the results). Subsequently, the latter regression was utilized to fit social security probability for each worker in the EUS data.

Underemployment and Overemployment: Overemployment and underemployment are typically taken into account when investigating job quality, as they reflect the level of decent hours of work that an employee enjoys. Information available from the EUS on weekly working hours, are used to determine underemployment and overemployment. A worker spending more than 40 hours per week job is regarded as overemployed, while they are considered underemployed if they work less than 40 hours a week. As a result, two variables were created representing underemployment and overemployment. The absolute values of these two variables were standardized, as was performed in the case of real wages and salaries.

To obtain scores representing the JQI in Jordan, on the basis of the above four underlying constructs, Factor Analysis (FA) technique was applied. FA is popular in studies of job quality index. In general, this method is more appropriate than others such as principle components analysis, if the production of a limited number of factors out of observed variables follows a particular theory (Tabachnick and Fidell, 2001). As far as job quality is concerned, the effect of each variable used in this study on JQI can theoretically be expected. Wages and social security associate positively with job quality. On the other hand, overemployment and underemployment inversely influence job quality. Table 3 reports the results of FA conducted in the study. Loadings of the variables, which reflect the role of each construct in composing scores of the index, apparently complement the previous initial predictions.

\section{Main Findings}

\subsection{JQI in Jordan over the Period 2000-2007}

Quality of jobs, whether those created or already existing jobs, might change over time in response to overall economic circumstances and labor market dynamics. Based on Figure 1, it is obvious that the JQI in Jordan has on average witnessed downward changes, particularly from 2001 through 2005. One possible explanation for this trend is that the Jordanian economy is highly vulnerable to external political and economic shocks. The latest Gulf War (the invasion of Iraq) coupled with increases in oil prices probably influenced the variables composing the index. As mentioned above, Jordan's economic policies have gradually integrated the national economy with the world economy. For example, as a result of the several bilateral and multilateral free trade agreements signed by the government, exports grew substantially. Qualifying industrial zones (QIZs) are a particular source of export increases, where exports rose by 56.8\% in 2004 (Ministry of Industry and Trade, 2004). Of course, more jobs were created due to foreign direct investment in the economy, notably in QIZs. However, it is claimed that factories functioning in QIZs do not comply with Jordanian labor acts and 
regulations.

The mean JQI makes some progress after 2005. Wages and salaries have experienced noteworthy increases in the recent years, mainly in 2006 and 2007. Both public and private sectors decided to raise wages and salaries in response to soaring oil prices that participated in eroding real earnings in the economy. The government announced a plan to index wages and salaries in the public sector to the annual rate of inflation JD 110. Since 2007 , the SSD has embarked on new programs that aim to widen the social security coverage. These procedures possibly contribute to the remarkable increase in JQI made in 2007. However, it is definitely important at this stage to draw attention to the missing relevant JQI variables that would change the results of the JQI over time if included (see the previous section).

To shed more light on the development of job quality in Jordan, a visual representation of JQI distribution for 2000 and 2007 is given. Figure 2 depicts the kernel density distribution of JQI for the entire population of wage and salary workers for both years. Apart from the evidence that both distributions are similarly multimodal, the figure demonstrates that the distribution of the JQI slightly narrowed in 2007, leading to an increased percentage of jobs characterized by a moderate level of JQI. To further detect this possibility, the areas under the distribution curves are divided into three categories. The first represents good jobs, which are supposed to have on average higher real wages and salaries, lower levels of overemployment and underemployment, and greater probability of social security coverage. Jobs possessing a JQI higher than 0.5 are classified as good jobs. In contrast, a JQI falling between -0.5 and 0.5 are considered as representing fair jobs. Fair jobs should therefore score lower than good jobs with respect to the variables composing the index and better than poor jobs, which are in turn represented by a JQI of less than 0.5 . Figure 3 clarifies the growth of each category of jobs for the whole period (2000-07) as a percentage of the total jobs. Apparently, in 2007 the labor market regained almost the same percentage of good jobs that existed in 2000. The percentage of fair jobs has also increased in 2007 to a level that was even higher than it was in 2000. In addition, in 2007 the percentage of poor jobs declined in comparison with 2000. To sum up, this section provides evidence on the development of the JQI over time in Jordan. Despite the significant decline after 2000, the JQI appears to revive in 2007.

\subsection{JQI by Gender}

Gender equality in labor market lies at the heart labor market reform and policies adopted locally and internationally (ILO, 2010). Efforts are centered on empowering women economically, socially, and politically and integrating them into the labor market. In Jordan, women have achieved extraordinary improvements in terms of educational attainment. Yet female labor market participation rates remains low, despite the growth achieved in the recent years. Gaps in unemployment rates and earnings are in favor of males (see section 2 and Appendix 3). Figure 4 demonstrates JQI growth for 2000-07 for both female and male Jordanian wage and salary workers. Females significantly lag behind, with a below-zero mean JQIs in the middle of the period. The evidence regarding the gender gap in JQI found in this study adds a new dimension to gender discrepancy in the Jordanian labor market. Parallel to the general trend in the period of analysis, the JQI of females' jobs has begun to grow positively from 2005 onward, partly due to recent increases in wages and salaries.

A finding of particular interest is the pattern of the gender gap in JQI over time. In Figure 4, the difference in JQI between both sexes is displayed and indicates no evidence of convergence between men and women. In fact, it seems that the gap widened even further in 2007. The average JQI for males in 2007, relative to 2006, outgrows females', resulting in a greater JQI gap in favor of males (the gap increased from 0.056 in 2006 to 0.094 in 2007). It is particularly useful to examine trends in the share of good and poor jobs relative to total jobs in each year of the period under investigation. Yet again, the labor market seems to favor male workers in the distribution of poor jobs and good jobs. For each year of the period, as evident in Figure 5, good jobs held by men represent a higher percentage of their total jobs than women's good jobs do. In 2007, this percentage increased for men to $31 \%$ from $25 \%$ in 2006 , while it fell slightly for women from $23 \%$ to $21 \%$. As is quite evident in Figure 5, there has been a descending trend, with almost a 2\% average decrease annually, of percentage of poor jobs held by men. The percentage of poor jobs also dropped dramatically for females (from $19 \%$ in 2006 to $16 \%$ in 2007). Nevertheless, female workers are found to occupy a higher percentage of poor jobs compared with males (in 2007, $16 \%$ and $11 \%$ for females and males respectively).

\subsection{JQI across Education Levels}

Education is commonly considered a key mechanism through which individuals may enhance their labor market success. The leading economic theory of education, the human capital theory, assumes education as an investment of human capital, producing higher productivity and in effect more private and social returns. Thus, education is supposed to augment earnings, and is in turn assumed to associate positively with the JQI. However, the relationship between education and the other JQI variables used in this study, particularly overemployment 
and underemployment, is not straightforward. With respect to the JQI as measured in this study, we found that workers having at least basic education are less likely to hold jobs characterized by lower levels of job quality, in contrast with other education al levels. The JQI differentiates less obviously among other levels of education (vocational, secondary, and higher education). This possibly signals the existence of a well-known phenomenon prevailing in many labor markets, namely the issue of over-qualification. Nevertheless, more education has appeared to result in better JQI levels by the end of the period. In 2007, higher education ranks the highest followed by the other levels. These results are shown in Figure 6, which graphs the JQI for different education levels over the period 2000-07. Figures 7 and 8 visually analyze the role of education on the percentages of good and poor jobs relative to total jobs occupied by workers. The two figures show to a great extent the overall JQI trend presented in Figure 6. Similarly, on average, workers with basic education are less likely to be employed in good jobs than their counterparts with higher levels of education.

\subsection{JQI across Age Groups}

An investigation of the JQI can give some clues to the development of job quality across generations, an analysis that may be of great importance for other labor market questions, in particular inequality between generations. In the context of the available Jordanian data, such an essential enquiry is hampered by the fact that surveys contain no information on a worker's previous employment history. In other words, one cannot determine whether the job of a particular worker is their first one and cannot identify when she/he got the current job. Despite this drawback, the JQI analysis based on worker's age remains important for the case of Jordan and may suggest some important findings. To do so, the JQI is averaged by age group and for males and females separately. Figures 9 and 10 display differences in the mean JQI by age group for each gender in 2000 and 2007, respectively. Most importantly, the figures reveal that female workers fall considerably below their male counterparts in terms of JQI in both 2000 and 2007. This result is consistent with the above-reported analysis on the JQI gender gap. The comparison between the two years (the beginning and end of the period) enables us to suggest a reason for the increasing gap in JQI in 2007. It is perhaps due to rising differences in the JQI of young entrants from both sexes to labor market. The JQI gender gap for younger age groups (ages 15-37) widens in 2007 compared with 2000, as appears in Figures 9 and 10. Strangely enough, the trends of the JQI curves for both males and females are concave. One potential reason of such an observation is the evident concavity of age-earning profiles. Also, as emphasized in section 3, the methodology of the study involves fitting a variable representing social security coverage relying on SSD data. The SSD is presently the main body in the country that bears the responsibility for social security coverage for workers in both public and private sectors. However, workers belonging to older age groups might not be well-represented by SSD data as they are perhaps covered by an earlier retirement system called the Civil Service System. Public sector workers, with secondary education and above, used to be covered by the latter system. The government decided in 1995 to cover its newly hired eligible staff, regardless of education, with the Social Security Law, which is implemented by SSD. In other words, the lower levels of JQI assigned to older age groups might partly be caused by limitations in the data utilized in compiling the index.

\subsection{JQI across Economic Activities}

The economic development process, particularly in a rapid, modern, globalized economy, brings about structural changes in many respects. Some economic activities grow faster than others, while new production methods and types of professions emerge and others vanish. Correspondingly, earnings and other work conditions, such as working hours, might fluctuate in certain economic activities over time. Accordingly, job quality may differ across economic activities as well. The most interesting finding regarding the JQI in Jordan when economic activities were taken into account was that those workers employed in the agriculture sector tended to have a lower JQI than others, followed by construction jobs, which ranked second from the bottom. This result is consistent over the whole period of the study. Workers in the fields of education and health are found to obtain jobs with a mean JQI higher than the previous two activities, but significantly lower than most of the other sectors. Figure 11 compares JQI across economic activities in Jordan for 2000 and 2007. The shape of both trends is clearly similar to a great extent, supporting the result reported above that the JQI revived in 2007. Moreover, the average JQI of activities belonging to the real estate sector has greatly increased in 2007 compared to 2000, while a noticeable drop has occurred for electricity and water activities. Female workers normally crowd into particular activities like farming, education, and nursing. This might in part explain their lower levels of JQI in agriculture, education, and health occupations. With respect to education, an important debate is taking place over the viewpoint that salaries of teachers worsen relative to other occupations. Paying teachers lower wages and salaries coupled with a lack of social and health coverage is a common practice in private schools, notably kindergartens. Agriculture's low JQI corresponds with labor market dynamics in Jordan. Agriculture's contribution to GDP in Jordan has declined over time, reaching a very low level of about $4 \%$ in 
2007. This reflects the diminishing attention devoted to this activity relative to others, particularly services and manufacturing. Also, work contracts in agriculture are not subject to important regulations and articles of the Labor Act and Social Security Law, most importantly minimum wage rates and retirement allowances.

\section{Conclusion}

This study has assessed the quality of the jobs created in Jordan for wage and salary workers through compiling a JQI for the period 2000-07. Four key dimensions were taken into account: real wages, overemployment, underemployment, and social security. The study presents some interesting findings. First, the JQI tends to have revived in 2007 compared with mid-2000s, reaching similar levels of those prevailing in 2000. Second, there exists a persistent gender gap in favor of male workers, whose jobs are characterized by a higher JQI. This finding does not change even when taking into account other intervening variables, particularly worker's age. Good jobs as a percentage of total jobs held by females appear to decline in 2007, unlike males, whose percentage of good jobs has grown in the same year. Therefore, no sign of convergence in job quality between males and females is detected. Third, the JQI varies across education al levels, however, less obviously. Workers with basic education and lower are found to obtain considerably poorer jobs and jobs that are generally characterized by a lower JQI. Fourth, the JQI differs across age groups. New entrants and workers on the verge of retirement are more likely to have lower job quality in comparison with other workers belonging to middle age groups. Fifth, the quality of jobs belonging to agricultural activities is found to be on average, lower than other activities. On the other hand, real estate activities tend to have higher job quality than other sectors, especially in 2007.

The analysis relies mainly on data obtained from the EUS. However, the study additionally uses information from other micro-level large-scale data sources, namely the IES and SSR, to acquire essential dimensions of job quality that are not available in the EUS. This methodological procedure should be borne in mind when one considers the findings of the study. This research is therefore a first step toward making an assessment of the JQI in the context of Jordan. In addition to the fact that no single microdata set includes sufficient job quality variables, the data sources in Jordan do not measure some job quality related dimensions. These include worker voice and unionization rates, paid vacation, paid sick leaves, the presence of a formal employment contract, and the regularity of employment. The DOS and other governmental entities are advised to organize regular job quality surveys that take into account the multidimensional nature of job quality. Also, the DOS should improve existing surveys by adjusting them for job quality measurement purposes. Doing so will make examining job quality indices easier, enhancing their precision and their comparability over time and across different labor groups.

\section{Acknowledgement}

An earlier version of this paper is a working paper titled "Job Quality in Jordan: An analysis based on a job quality index (JQI)", Gender and Work in the MENA region working paper series, No. 4, August, 2009. The authors should also thank Professor Ragui Assad, Minnesota University, for his helpful comments and assistance.

\section{References}

Acemoglu, D. (2001). Good Jobs Versus Bad Jobs. Journal of Labor Economics, 19 (1), pp. 1-22. http://dx.doi.org/10.1086/209978

Anker, R., Chernyshev, I., Egger, P., Mehran F., \& Ritter, J. (2003). Measuring Decent Work with Statistical Indicators. International Labor Review, 142 (2), pp. $147-177$. http://dx.doi.org/10.1111/j.1564-913X.2003.tb00257.x

Bazillier. R. (2008). Core Labor Standards and Development: Impact on Long-term Income. World Development 36 (1), pp. 17-39. http://dx.doi.org/10.1016/j.worlddev.2007.02.010

Central Bank of Jordan. (2007). Annual Statistical Report. Amman: CBJ

Department of Statistics of Jordan. (2010). The analysis report of the Newly-created Jobs Survey of the year (2009). [Online] Available: http://www.dos.gov.jo/sdb_pop/sdb_pop_a/yearly_2009.pdf (Last accessed 25 December 2010).

Enchautegui, M. (2008). The Job Quality of U.S. Immigrants. Industrial Relations, 47 (1), pp. 108-113. http://dx.doi.org/10.1111/j.1468-232X.2008.00506.x

Green, F. (2006). Demanding work: The paradox of job quality in the affluent society. Princeton: Princeton University Press.

Harmon, C., Oosterbeek, H., \& Walker I. (2003). The returns to education: Microeconomics. Journal of 
Economic Surveys, 17(2), pp. 115-155. http://dx.doi.org/10.1111/1467-6419.00191

Howell, D., \& Diallo, M. (2007). Charting US Economic Performance with Alternative Labor Market Indicators: The Importance of Accounting for Job Quality. Working Paper, SCEPA. [Online] Available: http://www.newschool.edu/cepa/publications/workingpapers/SCEPA\%20Working\%20Paper\%202007-6.pdf (last accessed 11 March 2009).

ILO. (2010). Decent work for domestic workers. Report IV (1), International Labor Conference, $99^{\text {th }}$ Session, Geneva. http://www.ilo.org/wcmsp5/groups/public/@ed_norm/@relconf/documents/meetingdocument/wcms_104700.pd $\mathrm{f}$ (Last accessed 1 March 2011).

Leschke, L., Watt, A., \& Finn, M. (2008). Putting a number on job quality? Constructing a European Job Quality Index. Working Paper, European Trade Union Institute for Research, Education, and Health and Safety. [Online] Available:

http://www.laborline.org/GEIDEFile/08_WP2008_03_avec_C1.PDF?Archive=19765791588\&File=08+WP2008 $+03+$ avec+C1_PDF (Last accessed 3 April 2009).

Lower-Basch, E. (2007). Opportunity at Work: Improving Job Quality. Policy Paper, (1), Center for Law and Social Policy. Opportunity at Work Series. [Online] Available: http://www.clasp.org/publications/oaw_paper1_full.pdf(Last accessed 13 March 2009).

Ministry of Industry and Trade. (2004). Annual Bulletin. Amman.

Tabachnick, B., \& Fidell, L. (2001). Using multivariate statistics. (4th ed.). Boston: Allyn and Bacon.

Tangian, A. (2007). Is flexible work precarious? A study based on the $4^{\text {th }}$ European survey of working conditions 2005. WSI Discussion paper (153). [Online] Available: http://opus.zbw-kiel.de/volltexte/2008/6924/pdf/p_wsi_diskp_153_e.pdf (Last accessed 17 March 2009).

UNESCO Institute for Statistics \& OECD. (2005). Education trends in perspective, analysis of the world education indictors. [Online] Available: http://www.uis.unesco.org/TEMPLATE/pdf/wei/WEI2005.pdf (Last accessed 25 April 2009).

Table 1. Unemployment rate in Jordan by sex (2000-2007)

\begin{tabular}{|c|c|c|c|}
\hline Year & Males & Females & Total \\
\hline 2000 & $12.3 \%$ & $21.0 \%$ & $13.7 \%$ \\
\hline 2001 & $13.7 \%$ & $20.5 \%$ & $14.7 \%$ \\
\hline 2002 & $14.0 \%$ & $21.9 \%$ & $15.3 \%$ \\
\hline 2003 & $13.4 \%$ & $20.8 \%$ & $14.5 \%$ \\
\hline 2004 & $11.8 \%$ & $16.5 \%$ & $12.5 \%$ \\
\hline 2005 & $12.8 \%$ & $25.9 \%$ & $14.8 \%$ \\
\hline 2006 & $11.9 \%$ & $25.0 \%$ & $14.0 \%$ \\
\hline 2007 & $10.3 \%$ & $25.6 \%$ & $13.1 \%$ \\
\hline
\end{tabular}

Source: Almanar Database based on EUSs conducted by DOS.

Table 2. Refined labor force participation rate in Jordan by sex (2000-2007)

\begin{tabular}{|c|c|c|c|}
\hline Year & Males & Females & Total \\
\hline 2000 & 66.1 & 12.3 & 39.4 \\
\hline 2001 & 65.5 & 11.7 & 38.8 \\
\hline 2002 & 64.2 & 12.3 & 38.4 \\
\hline 2003 & 63.2 & 11.2 & 37.4 \\
\hline 2004 & 63.7 & 10.4 & 37.4 \\
\hline 2005 & 64.4 & 11.7 & 38.3 \\
\hline 2006 & 63.1 & 11.9 & 37.7 \\
\hline 2007 & 64.4 & 14.7 & 39.8 \\
\hline
\end{tabular}

Source: Almanar Database based on EUSs conducted by DOS. 
Table 3. EUS samples and number of wage workers surveyed (2000-2007)

\begin{tabular}{|c|c|c|c|c|c|}
\hline Year & $\begin{array}{c}\text { Total } \\
\text { Sample }\end{array}$ & Males & Females & $\begin{array}{c}\text { Wage and salary } \\
\text { workers }\end{array}$ & $\begin{array}{c}\text { Total } \\
\text { workers }\end{array}$ \\
\hline 2000 & 196,057 & 100,366 & 95,691 & $33,752(\% 15)$ & 40,678 \\
\hline 2001 & 193,413 & 98,867 & 94,546 & $32,270(\% 15)$ & 38,646 \\
\hline 2002 & 223,921 & 114,548 & 109,373 & $37,222(\% 15)$ & 44,385 \\
\hline 2003 & 220,636 & 112,856 & 107,780 & $37,325(\% 15)$ & 43,883 \\
\hline 2004 & 78,731 & 40,524 & 38,207 & $13,696(\% 14)$ & 16,162 \\
\hline 2005 & 21,6636 & 110,097 & 106,539 & $36,751(\% 16)$ & 42,977 \\
\hline 2006 & 212,608 & 107,970 & 104,638 & $37,117(\% 15)$ & 42,877 \\
\hline 2007 & 265,275 & 135,616 & 129,659 & $49,865(\% 17)$ & 57,930 \\
\hline Total & $\mathbf{1 , 6 0 7 , 2 7 7}$ & $\mathbf{8 2 0 , 8 4 4}$ & $\mathbf{7 8 6 , 4 3 3}$ & $\mathbf{2 7 7 , 9 9 8} \mathbf{( \% 1 5 )}$ & $\mathbf{3 2 7 , 5 3 8}$ \\
\hline
\end{tabular}

(\%) represents females' percentage to the total number of wage and salary workers.

Table 4. IES sample and number of wage workers surveyed in 2006

\begin{tabular}{|c|c|c|c|c|c|}
\hline Year & $\begin{array}{c}\text { Total } \\
\text { Sample }\end{array}$ & Males & Females & $\begin{array}{c}\text { Wage and salary } \\
\text { workers }\end{array}$ & Total workers \\
\hline 2006 & 73,949 & 36,905 & 37,044 & $12,521(\% 20)$ & 15,017 \\
\hline
\end{tabular}

(\%) represents females' percentage to the total number of wage and salary workers.

Table 5. SSR by gender in period 2000-2007

\begin{tabular}{|c|c|c|c|}
\hline Year & Total Personal Records & Males & Females \\
\hline 2000 & 366,330 & 287,461 & 78,869 \\
\hline 2001 & 381,898 & 291,626 & 90,272 \\
\hline 2002 & 416,374 & 312,802 & 103,572 \\
\hline 2003 & 467,044 & 349,832 & 117,212 \\
\hline 2004 & 519,372 & 385,766 & 133,606 \\
\hline 2005 & 592,230 & 440,388 & 151,842 \\
\hline 2006 & 661,651 & 492,399 & 169,252 \\
\hline 2007 & 724,167 & 541,080 & 183,087 \\
\hline Total & $\mathbf{4 , 1 2 9 , 0 6 6}$ & $\mathbf{3 , 1 0 1 , 3 5 4}$ & $\mathbf{1 , 0 2 7 , 7 1 2}$ \\
\hline
\end{tabular}

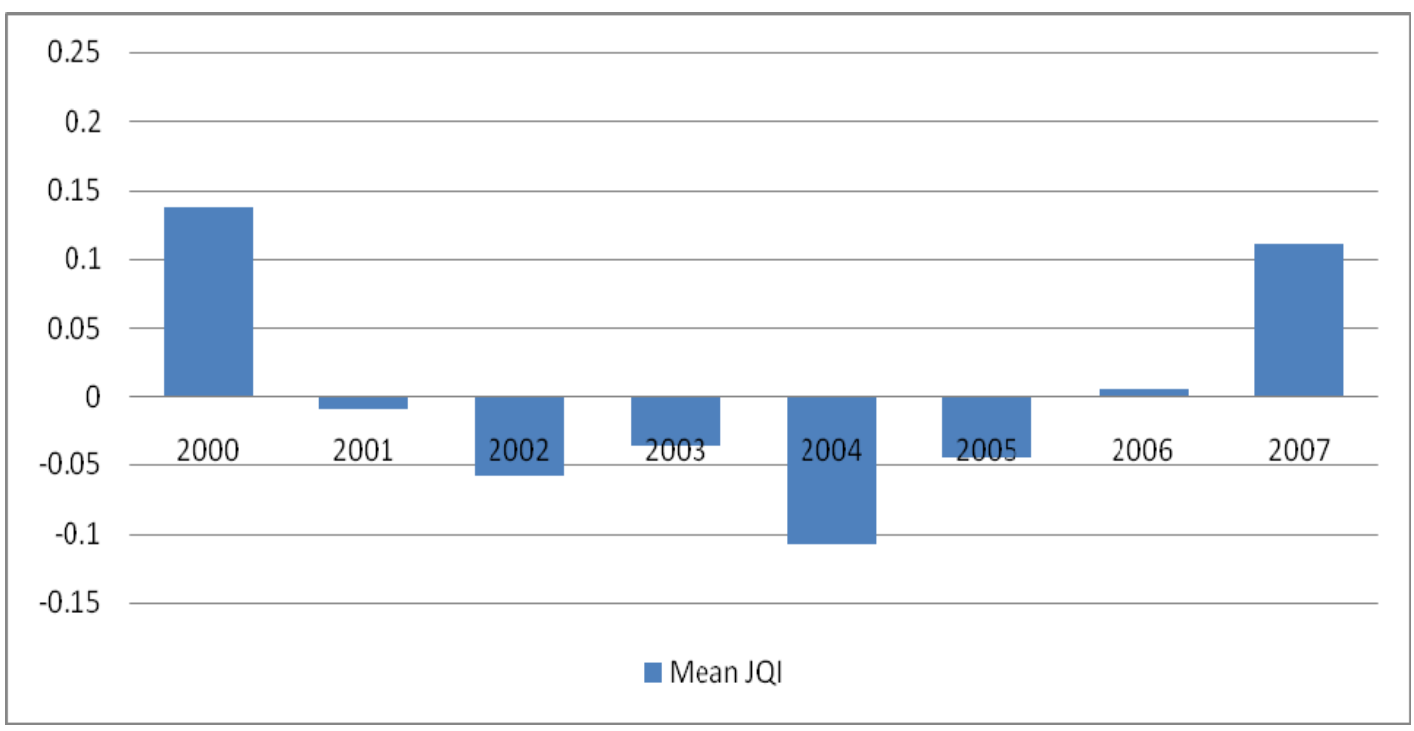

Figure 1. Mean standardized JQI in Jordan for the period 2000-2007 (All wage and salary workers) 


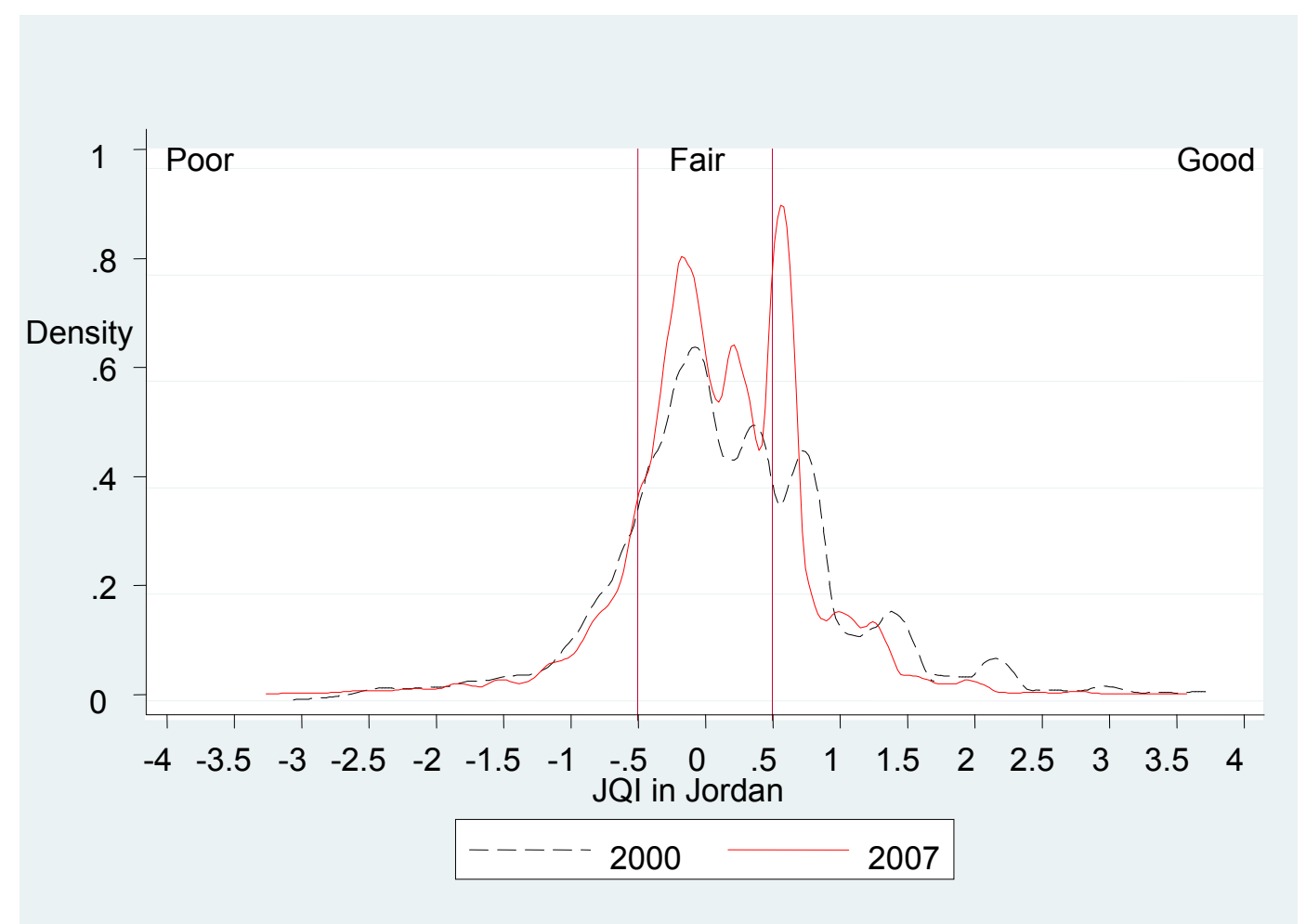

Figure 2. Kernel density distribution of standardized JQI for 2000 and 2007

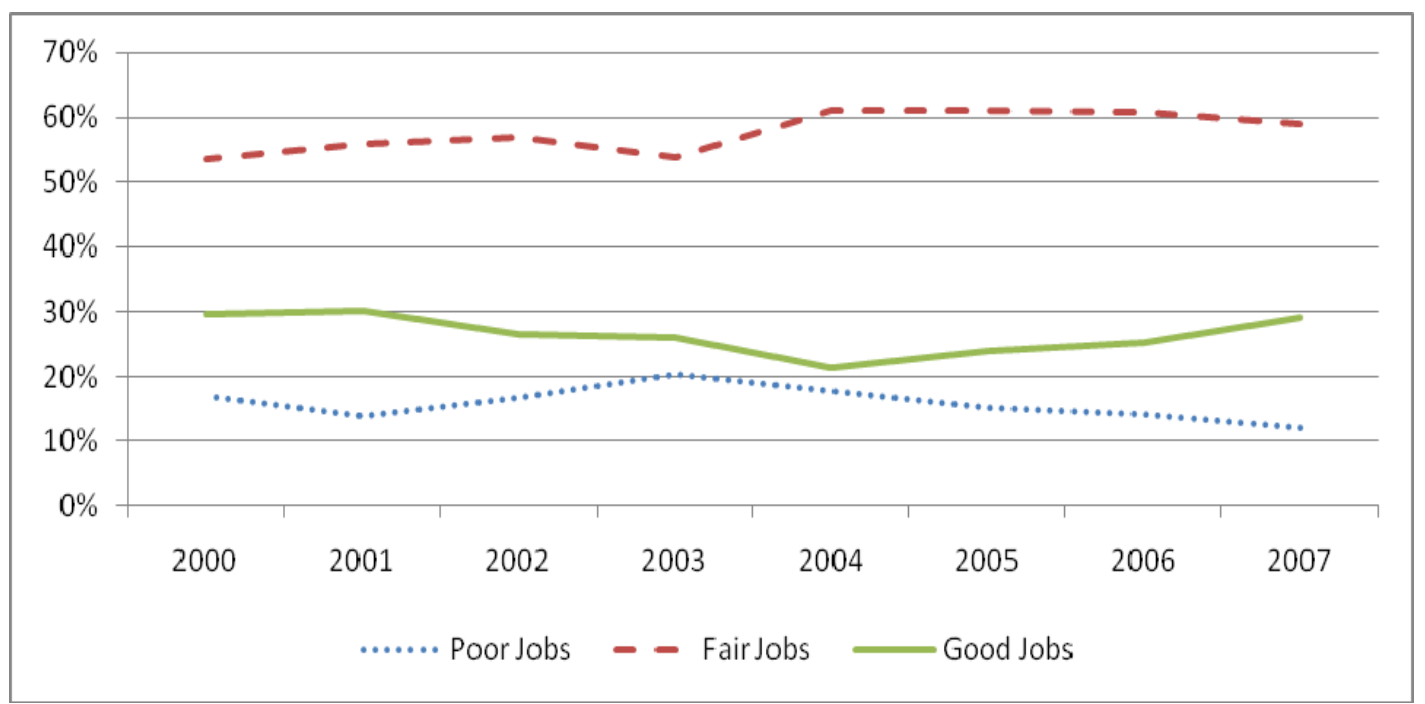

Figure 3. Trends of percentages of good, fair and poor jobs for 2000-2007 (All wage and salary workers) 


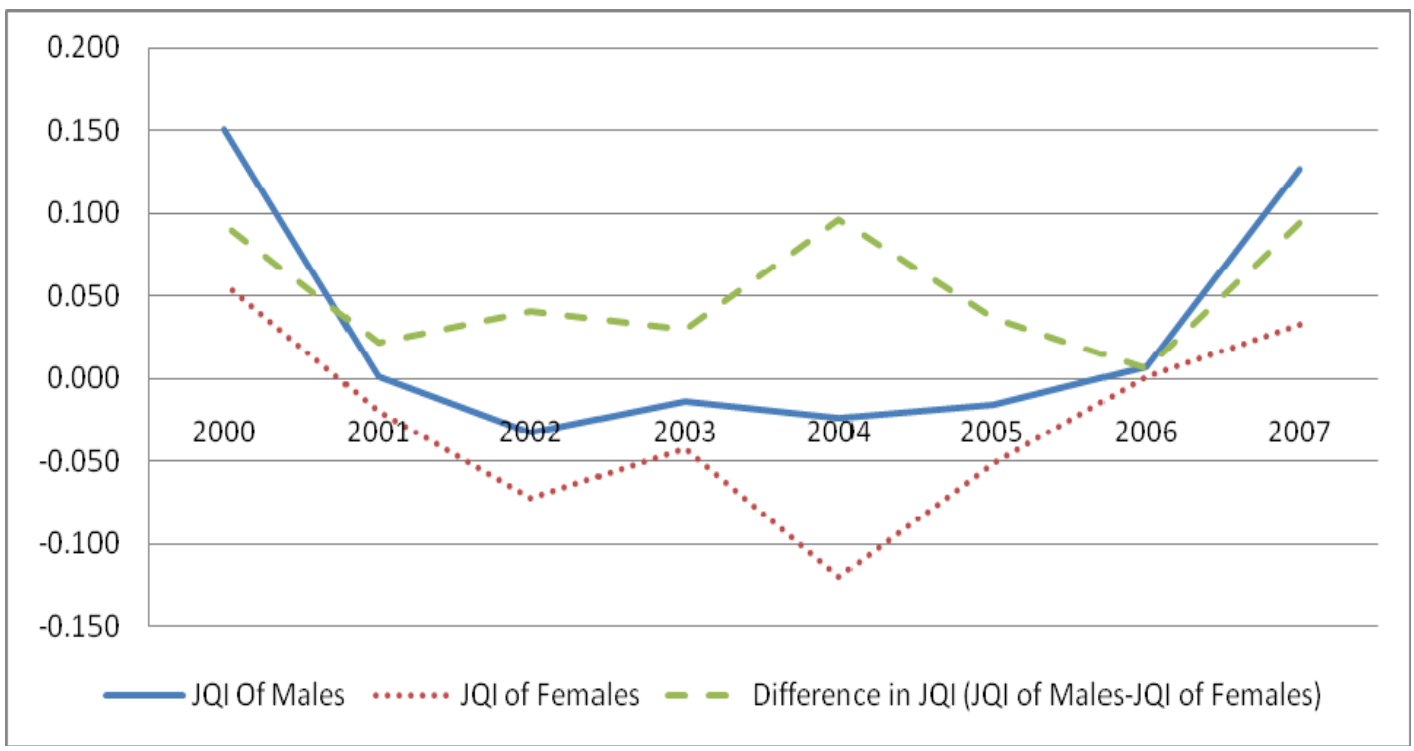

Figure 4. Mean standardized JQI in Jordan for males and females workers (2000-2007)

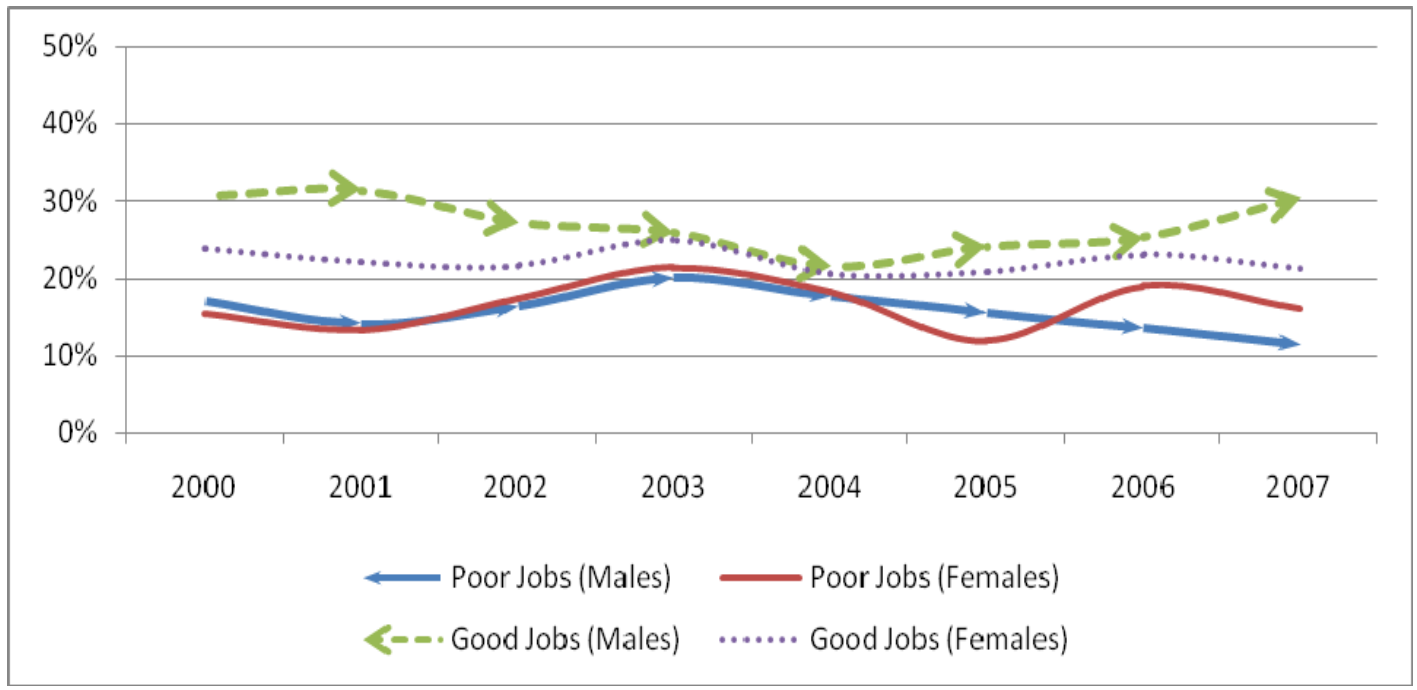

Figure 5. Trends of percentage of good and poor jobs (relative to total jobs) by sex

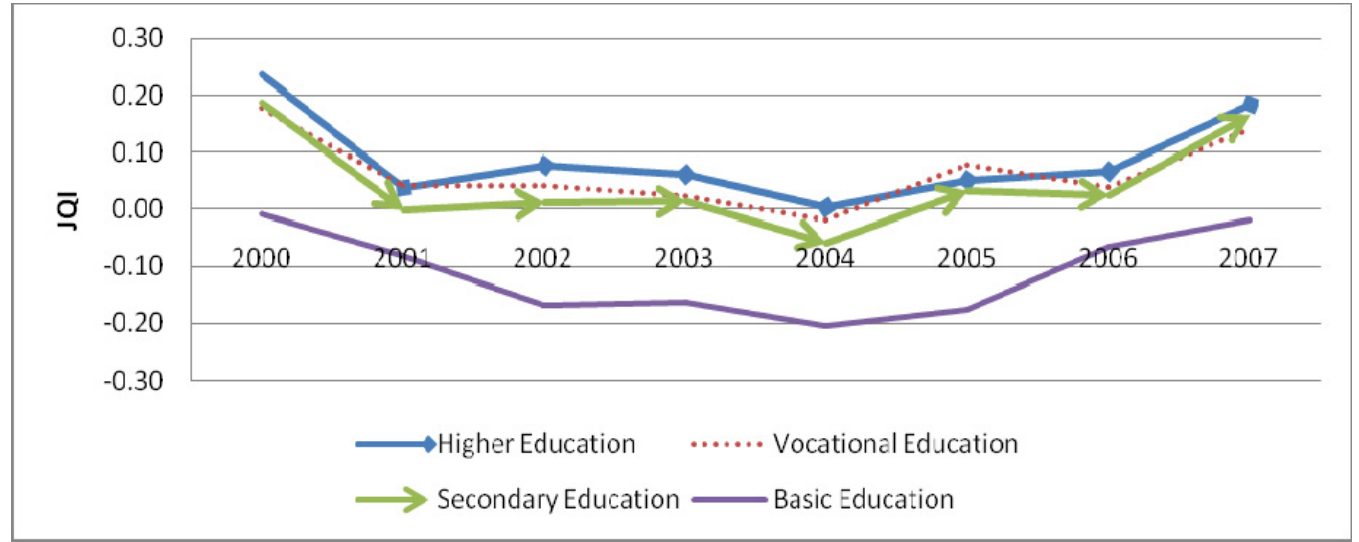

Figure 6. Mean standardized JQI in Jordan by education level for 2000-2007 


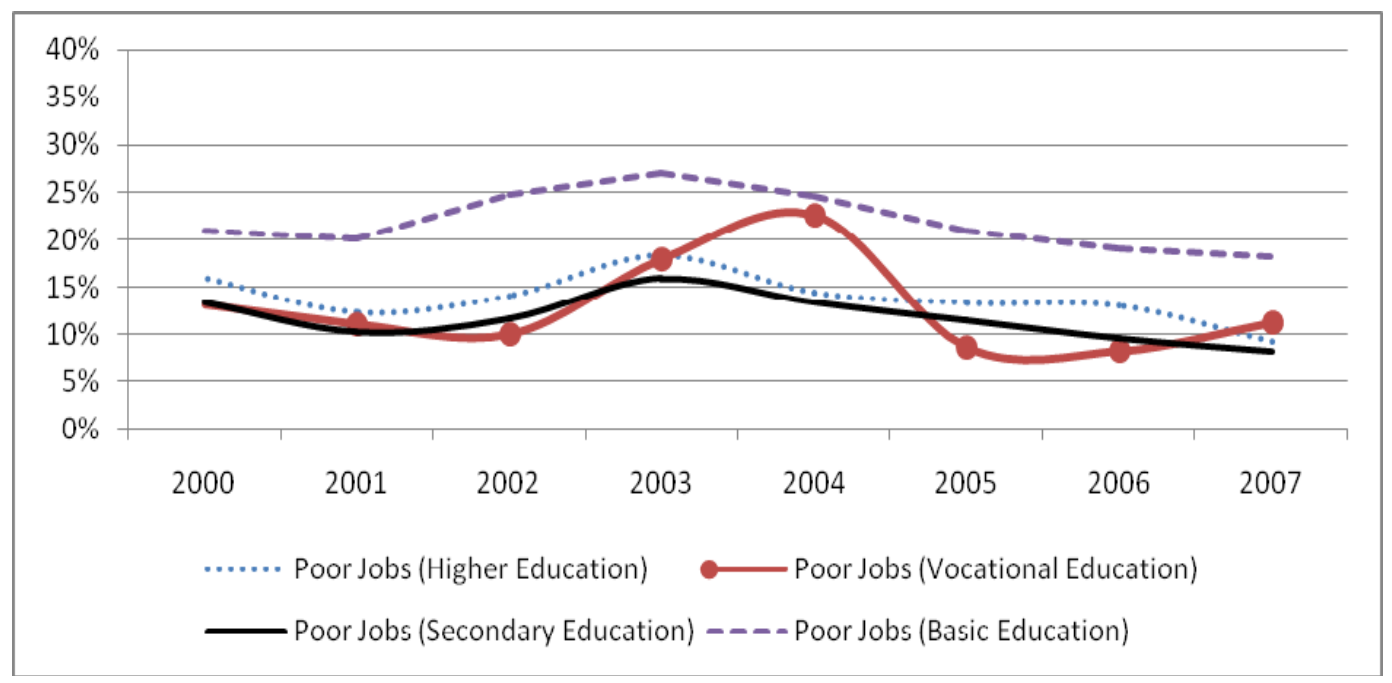

Figure 7. Trends of poor jobs shares (relative to total jobs) by education level

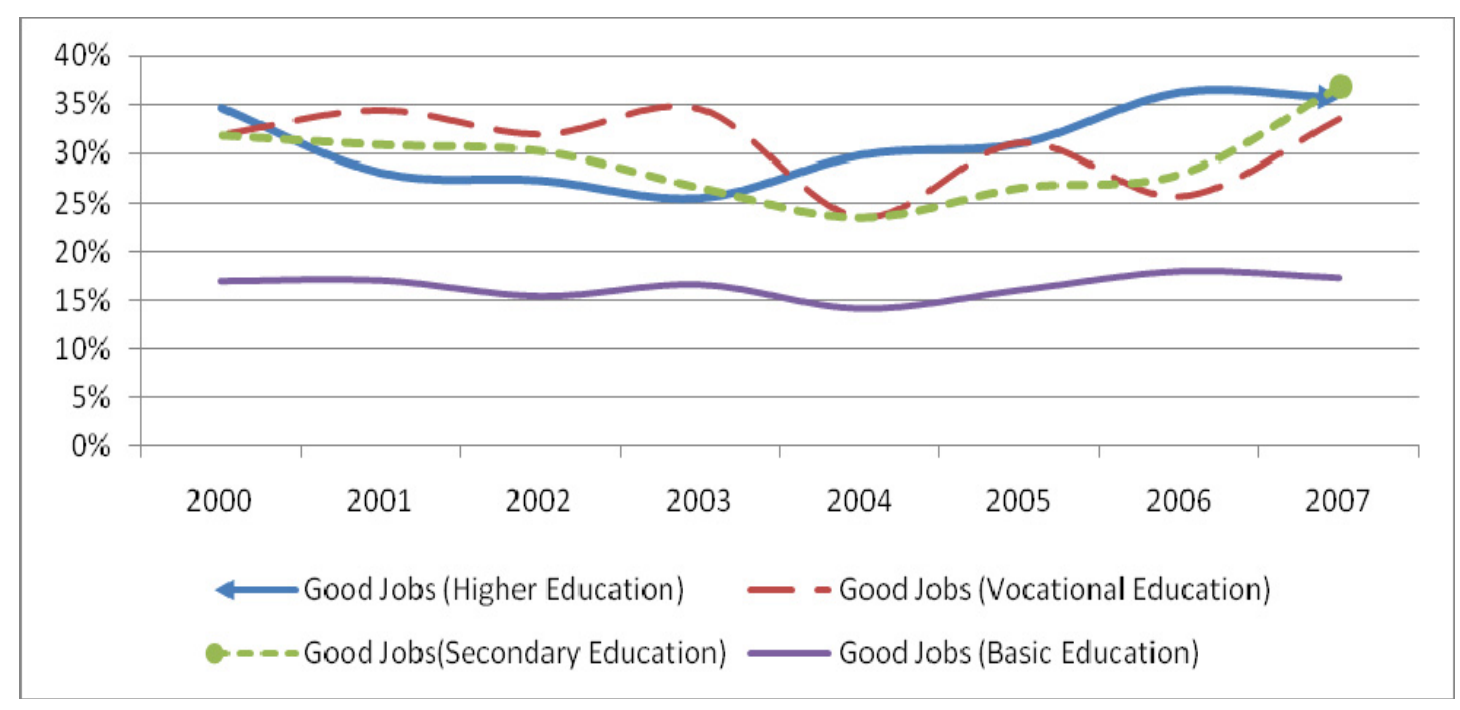

Figure 8 . Trends of good jobs shares (relative to total jobs) by education level

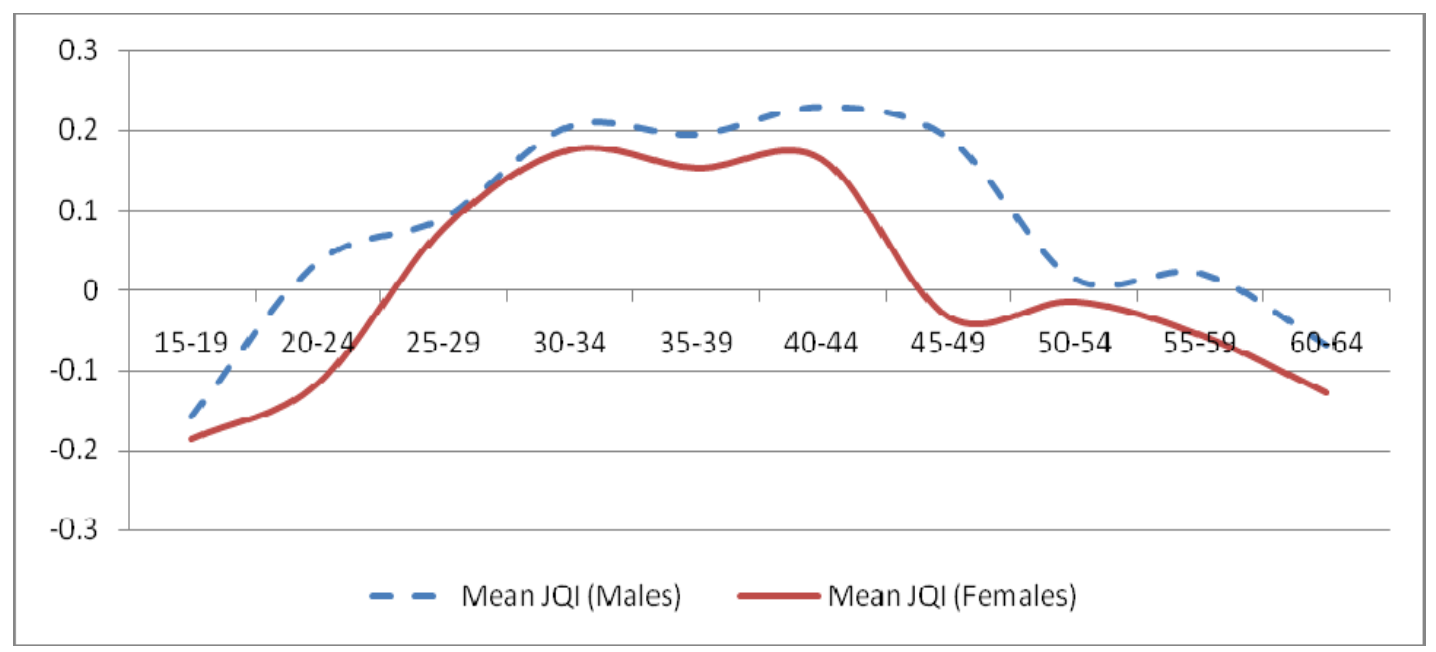

Figure 9. Mean standardized JQI in Jordan for males and females workers by age group in 2000 


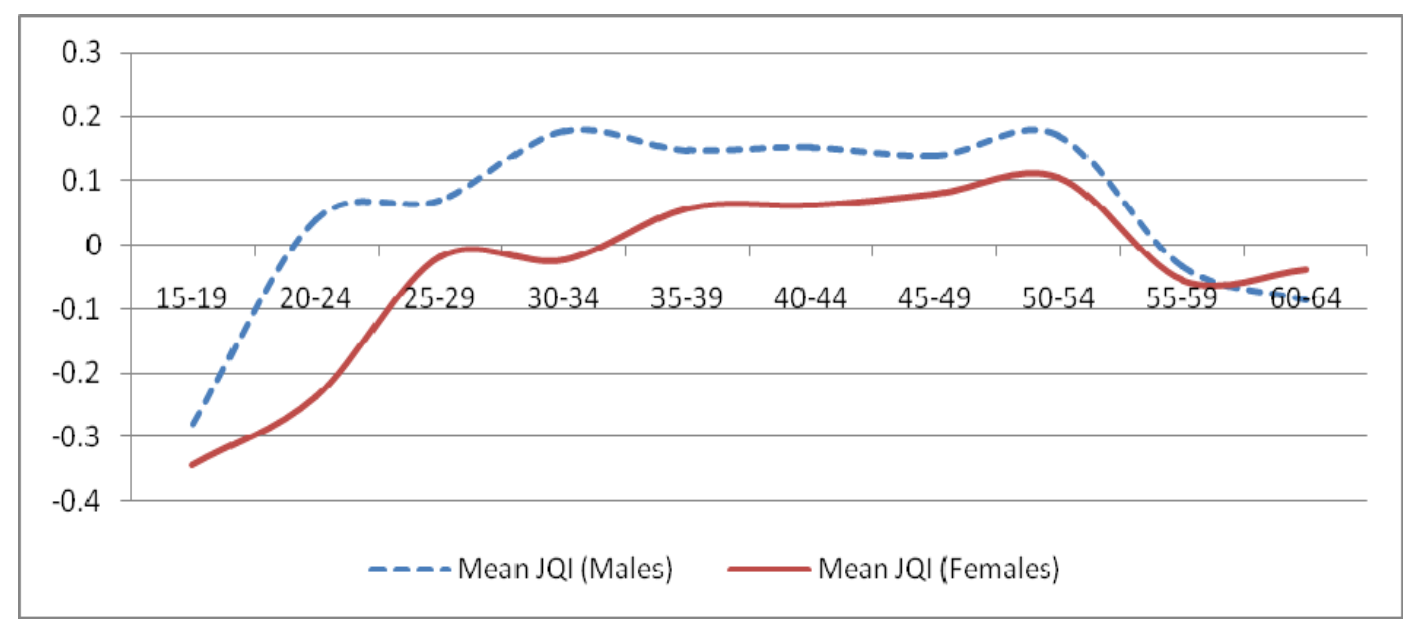

Figure 10. Mean standardized JQI in Jordan for males and females workers by age group in 2007

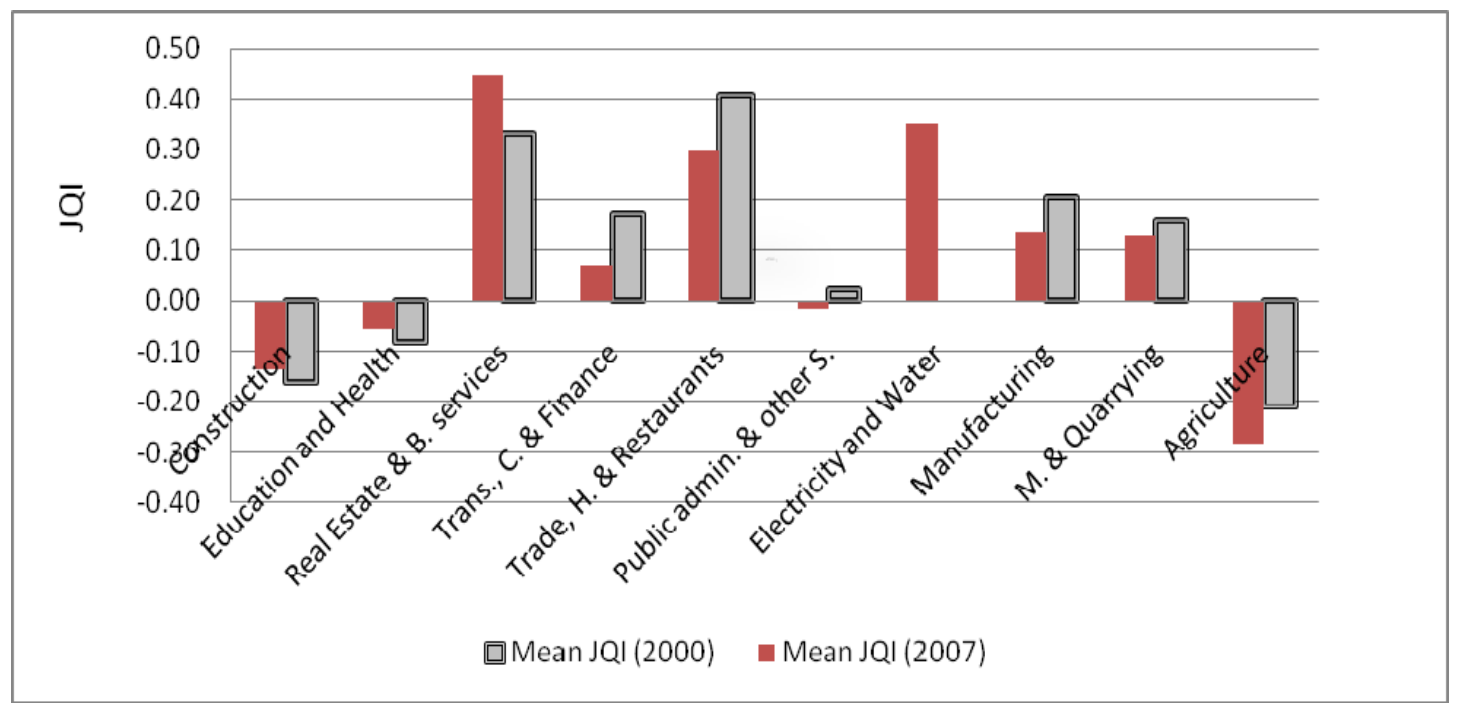

Figure 11. Mean standardized JQI in Jordan for all workers by economic activities in 2000 and 2007

Note: Some of the categories in the figure are abbreviated. Appendix 4 clarifies the economic activity categories in detail.

Appendix 1: Factor Analysis Results (Variables: Real Wages and Salaries, Social Security Coverage, Underemployment and Overemployment)

\begin{tabular}{|c|c|c|c|c|}
\hline Factor & Eigenvalue & Difference & Proportion & Cumulative \\
\hline 1 & 1.75 & 1.560 & 1.0194 & 1.0194 \\
\hline 2 & 0.189 & 0.234 & 0.11 & 1.1294 \\
\hline 3 & -0.452 & 0.132 & -0.0263 & 1.103 \\
\hline 4 & -0.177 &. & -0.0103 & 1.000 \\
\hline
\end{tabular}

\begin{tabular}{|l|c|c|}
\hline \multicolumn{1}{|c|}{ Factor loadings } & Factor retained (JQI) & Uniqueness \\
\hline Standardized overemployment & -0.4121 & 0.8302 \\
\hline Standardized underemployment & -0.1627 & 0.9735 \\
\hline Standardized Real wages and salaries & 0.9044 & 0.1821 \\
\hline Social security coverage & 0.8565 & 0.2664 \\
\hline
\end{tabular}


Appendix 2: Results of Multiple Regression (Dependant: In Wages) Using IES Data

\begin{tabular}{|l|c|c|c|}
\hline \multicolumn{1}{|c|}{ Explanatory variables } & Coefficients & t & P>t \\
\hline Sex (Male=0) & -0.21 & -37.62 & 0.00 \\
\hline Economic Sector (Public sector=0) & -0.05 & -14.11 & 0.00 \\
\hline Education level (Reference category= Illiterate) & \multicolumn{3}{l|}{} \\
\hline Read \& Write & 0.05 & 1.64 & 0.10 \\
\hline Elementary & 0.13 & 4.08 & 0.00 \\
\hline Preparatory & 0.23 & 7.62 & 0.00 \\
\hline Basic & 0.29 & 9.32 & 0.00 \\
\hline Vocational & 0.32 & 9.18 & 0.00 \\
\hline Secondary & 0.37 & 12.22 & 0.00 \\
\hline Intermediate Diploma & 0.50 & 16.24 & 0.00 \\
\hline BA & 0.76 & 24.89 & 0.00 \\
\hline Postgraduate & 1.08 & 32.72 & 0.00 \\
\hline Experience & 0.03 & 40.46 & 0.00 \\
\hline (Experience) ${ }^{2}$ & -0.0003 & -19.49 & 0.00 \\
\hline Constant & 4.85 & 151.49 & 0.00 \\
\hline R-squared =0.3392, Adj R-squared=0.3389, F =1208.09, Prob > F =0.000 & & \\
\hline
\end{tabular}

Appendix 3: Results of Multiple Regression (Dependant: In Average Wages) Using EUS Data

\begin{tabular}{|l|c|c|c|}
\hline \multicolumn{1}{|c|}{ Explanatory variables } & Coefficients & t & P>t \\
\hline Sex (Male=0) & -0.21 & -98.40 & 0.00 \\
\hline Economic Sector (Public sector=0) & -0.05 & -37.15 & 0.00 \\
\hline Education level (Reference category= Illiterate) & \multicolumn{1}{l|}{} \\
\hline Read \& Write & 0.07 & 6.74 & 0.00 \\
\hline Elementary & 0.15 & 14.49 & 0.00 \\
\hline Preparatory & 0.25 & 24.75 & 0.00 \\
\hline Basic & 0.31 & 30.35 & 0.00 \\
\hline Vocational & 0.34 & 29.59 & 0.00 \\
\hline Secondary & 0.40 & 39.64 & 0.00 \\
\hline Intermediate Diploma & 0.52 & 51.16 & 0.00 \\
\hline BA & 0.81 & 79.39 & 0.00 \\
\hline Postgraduate & 1.11 & 101.69 & 0.00 \\
\hline Year of survey (Reference category=2006) & -0.13 & -47.72 & 0.00 \\
\hline 2000 & -0.10 & -34.98 & 0.00 \\
\hline 2001 & -0.09 & -34.13 & 0.00 \\
\hline 2002 & -0.07 & -26.19 & 0.00 \\
\hline 2003 & -0.05 & -12.23 & 0.00 \\
\hline 2004 & -0.04 & -13.11 & 0.00 \\
\hline 2005 & 0.06 & 25.79 & 0.00 \\
\hline 2007 & 0.03 & 128.69 & 0.00 \\
\hline Experience & -0.0004 & -69.97 & 0.00 \\
\hline (Experience) $^{2}$ & 4.79 & 438.91 & 0.00 \\
\hline Constant & & \\
\hline R-squared =0.4009, Adj R-squared=0.4008, F =7632.86, Prob $>\mathrm{F}=0.00$ & & \\
\hline
\end{tabular}


Appendix 4: Results of OLS Regression (Dependant: Probability of Social Security) Using SSR Data

\begin{tabular}{|c|c|c|c|}
\hline Explanatory Group Variables & Coefficient & $\mathbf{t}$ & $\mathbf{P}>\mathbf{t}$ \\
\hline Sex $($ Male $=0)$ & -0.01 & -0.89 & 0.37 \\
\hline Economic Sector (Public sector $=0$ ) & 0.052 & 34.17 & 0.00 \\
\hline $\begin{array}{l}\text { Age group (Reference category }=15-19) \\
20-24\end{array}$ & -0.02 & -0.49 & 0.63 \\
\hline $25-29$ & -0.01 & -0.42 & 0.68 \\
\hline $30-34$ & -0.01 & -0.30 & 0.77 \\
\hline $35-39$ & -0.02 & -0.68 & 0.50 \\
\hline $40-44$ & -0.02 & -0.67 & 0.50 \\
\hline $45-49$ & -0.02 & -0.71 & 0.48 \\
\hline $50-54$ & -0.02 & -0.71 & 0.48 \\
\hline $55-59$ & -0.18 & -5.58 & 0.00 \\
\hline $60-64$ & -0.54 & -15.11 & 0.00 \\
\hline \multicolumn{4}{|c|}{$\begin{array}{l}\text { Economic activity (Reference category }=\text { Agriculture and } \\
\text { Hunting) }\end{array}$} \\
\hline Mining and Quarrying & 0.19 & 6.09 & 0.00 \\
\hline Manufacturing & 0.26 & 7.75 & 0.00 \\
\hline Electricity and Water & 0.33 & 9.15 & 0.00 \\
\hline Construction & 0.16 & 5.19 & 0.00 \\
\hline Trade, Hotels and Restaurants & 0.15 & 4.90 & 0.00 \\
\hline Transport, Storage, communication \& Finance & 0.15 & 4.95 & 0.00 \\
\hline Real Estate and Business Services & 0.58 & 19.84 & 0.00 \\
\hline Education and health & 0.17 & 5.64 & 0.00 \\
\hline Public Administration and other services & 0.14 & 4.79 & 0.00 \\
\hline $\begin{array}{l}\text { Year of survey (Reference category }=2000) \\
2001\end{array}$ & 0.01 & 0.48 & 0.63 \\
\hline 2002 & -0.05 & -1.96 & 0.05 \\
\hline 2003 & -0.04 & -1.48 & 0.14 \\
\hline 2004 & 0.20 & 6.40 & 0.00 \\
\hline 2005 & -0.03 & -1.01 & 0.31 \\
\hline 2006 & -0.02 & -0.76 & 0.45 \\
\hline 2007 & -0.02 & -0.79 & 0.43 \\
\hline Constant & -0.34 & -7.45 & 0.00 \\
\hline
\end{tabular}

